\title{
Molybdenum/cobalt/sulfur clusters: Models and precursors for hydrodesulfurization (HDS) catalysts
}

\author{
M David Curtis \\ Department of Chemistry, The University of Michigan, Ann Arbor, Michigan 48109-1055, USA
}

Sulfido clusters which incorporate molybdenum and a late transition metal, e.g. iron, cobalt or nickel, are readily prepared by the reactions of $\mathrm{Cp}_{2} \mathrm{Mo}_{2} \mathrm{~S}_{4}, \mathrm{Cp}_{2} \mathrm{Mo}_{2} \mathrm{~S}_{2}(\mathrm{SR})_{2}$ or $\mathrm{Cp}_{2} \mathrm{Mo}_{2}(\mathrm{CO})_{2}(\mathrm{SR})_{2}$ with $\mathrm{Fe}_{2}(\mathrm{CO})_{9}, \mathrm{Co}_{2}(\mathrm{CO})_{8}, \mathrm{Ni}(\mathrm{CO})_{4}, \mathrm{Cp}_{2} \mathrm{Ni}$, etc. The homogeneous reactions of the cluster $\mathrm{Cp}_{2} \mathrm{Mo}_{2} \mathrm{Co}_{2} \mathrm{~S}_{3}(\mathrm{CO})_{4}$ with thiols, thiophene, and phosphines are reviewed, as are some reactions of the clusters with metal oxide surfaces to produce heterogeneous catalysts for $\mathrm{CO}$ hydrogenation or hydrodesulfurization.

Keywords: Clusters, catalysis, hydrodesulfurization, bimetallic, desulfurization

\section{INTRODUCTION}

Measured as volume or value of product, the processes associated with fossil-fuel refining are among the most important industrial catalytic reactions. These catalyzed processes include hydrocracking, re-forming and hydrotreating for removal of sulfur (HDS), nitrogen (HDN), oxygen (HDO) or metals (HDM). A typical hydrotreating catalyst is prepared by adsorbing salts of molybdenum and cobalt onto high-surface-area alumina $\left(\mathrm{Al}_{2} \mathrm{O}_{3}\right)$, calcining and sulfiding. ${ }^{1-4}$ Other combinations of metals, e.g. tungsten plus nickel or molybdenum plus nickel, are also active, as are precious-metal sulfides, e.g. $\mathrm{RuS}_{2}{ }^{5}$

Only recently has general agreement emerged on the nature of the 'promoted' molybdenum catalysts (as the $\mathrm{Co} / \mathrm{Mo} / \mathrm{S}$ catalysts are known). ${ }^{6}$ Much of the present consensus is due to the elegant work of Topsøe et al., who have applied an array of modern spectroscopic methods, e.g. EXAFS and Mössbauer emission spectroscopy, to the catalyst and to model compounds. ${ }^{7}$ Topsøe's model suggests that small crystallites [ $c a$ $10 \AA(1 \mathrm{~nm})$ in diameter] of $\mathrm{MoS}_{2}$ are formed on the $\mathrm{Al}_{2} \mathrm{O}_{3}$ surface, and that the promoter ions, e.g. cobalt, coordinate to the edges of the basal planes of these $\mathrm{MoS}_{2}$ crystallites. On bulk $\mathrm{MoS}_{2}$ promoted with cobalt, the promoter ions clearly bind strongly to the edges of the basal planes. ${ }^{8}$

Although our knowledge of the physical nature of the supported $\mathrm{Co} / \mathrm{Mo} / \mathrm{S}$ catalysts has increased dramatically, the exact role of the promoter metal and the intimate details of the HDS mechanism are still poorly understood. Part of the reason for this is the lack of suitable organometallic models to help the interpretation of experimental results.

Organometallic modelling aids the study of heterogeneous catalysis in several important ways. At the most fundamental level, organometallic compounds provide structural models for possible surface species. Secondly, the spectroscopic properties of surface structures often resemble those of corresponding organometallic complexes. The reactivity of coordinated ligands can, and often does, mimic that of similar adsorbate molecules on catalyst surfaces. Finally, organometallic compounds may serve as precursors to specific surface structures. ${ }^{9}$

Only recently have good models of thiophene coordination and reactivity been developed with the detailed work of Rauchfuss ${ }^{10}$ and Angelici." Models for metal oxide ${ }^{12}$ or sulfide $^{13}$ catalyst surfaces are still underdeveloped, although Rakowski DuBois has demonstrated the possibility of considerable ligand-centered reactivity on sulfide surfaces (for example see Refs 14, 15). Very little work on bimetallic sulfides as models for HDS catalysts has appeared, but Adams et al. have investigated the reactions of organic sulfides with osmium clusters. ${ }^{16}$

This paper presents a brief review of our work on molybdenum/cobalt/sulfur clusters relevant to the HDS problem.

\section{SULFIDO BIMETALLIC CLUSTERS: SYNTHESIS AND STRUCTURE}

Bimetallic sulfide clusters with molybdenum (or tungsten) and iron, cobalt or nickel constituents are easily synthesized by the reactions of 


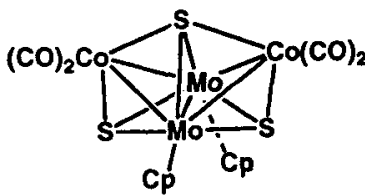

(1)

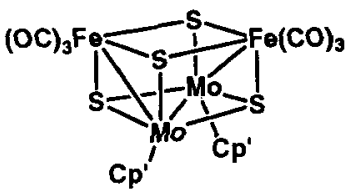

(3)

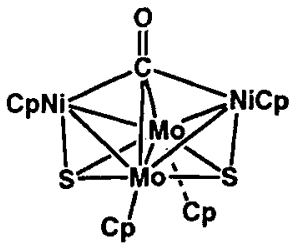

(5)

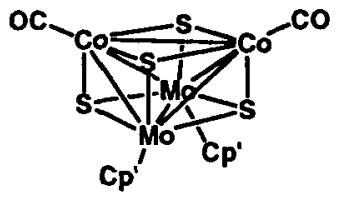

(2)

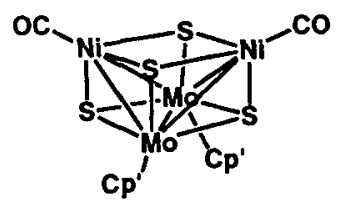

(4)

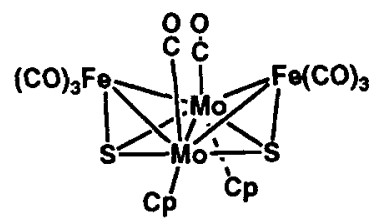

(6)

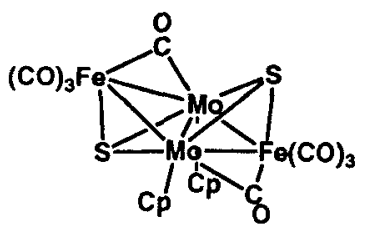

(7)

Figure 1

$\mathrm{Cp}_{2} \mathrm{Mo}_{2} \mathrm{~S}_{4}, \quad \mathrm{Cp}_{2} \mathrm{Mo}_{2} \mathrm{~S}_{2}(\mathrm{SR})_{2} \quad(\mathrm{R}=\mathrm{H}, \mathrm{Me}), \quad$ or $\mathrm{Cp}_{2} \mathrm{Mo}_{2}(\mathrm{SMe})_{2}(\mathrm{CO})_{2}$ with the carbonyls of iron, cobalt or nickel (Fig. 1, $\mathrm{Cp}=\mathrm{C}_{5} \mathrm{H}_{5}$ or $\left.\mathrm{C}_{5} \mathrm{H}_{4} \mathrm{Me}\right) .{ }^{17-20}$ Interestingly, $\mathrm{Co}_{2}(\mathrm{CO})_{8}$ reacts with $\mathrm{Cp}_{2} \mathrm{Mo}_{2} \mathrm{~S}_{4}$ to give the cubane cluster 2, but with $\mathrm{Cp}_{2} \mathrm{Mo}_{2} \mathrm{~S}_{2}(\mathrm{SR})_{2}$, the trisulfur cluster 1 is formed instead.

Cluster 5 , with a unique $\mu_{4}, \eta^{1}-\mathrm{CO}$ ligand, is produced by the reaction of $\mathrm{Cp}_{2} \mathrm{Ni}$ with $\mathrm{Cp}_{2} \mathrm{Mo}_{2} \mathrm{~S}_{2}(\mathrm{SMe})_{2}{ }^{20}$ This quadruply bridging carbonyl $\left(v_{\mathrm{CO}}=1654 \mathrm{~cm}^{-1}\right)$ may serve as a model for $\mathrm{CO}$ adsorbed on the four-fold hollows of 110 surfaces of face-centered cubic metals.

Isomeric clusters 6 and 7 are formed by the interaction of $\mathrm{Fe}_{2} \mathrm{~S}_{2}(\mathrm{CO})_{6}$ with the triply-bonded dimer, $\mathrm{Cp}_{2} \mathrm{Mo}_{2}(\mathrm{CO})_{4} \cdot{ }^{17}$
Most of the bimetallic sulfido clusters formed in the reactions described above are electronprecise, i.e. the number of valence shell electrons (VSE) is equal to $18 M-2 N$, where $M=$ number of metal vertices and $N=$ number of metal-metal bonds. Thus, these tetrametallic clusters have 60 VSE for cubanes with six M-M bonds, 62 VSE for 'butterflies' with $5 \mathrm{M}-\mathrm{M}$ bonds, etc. Cluster 1 is a notable exception. This cluster has five $\mathbf{M}-\mathbf{M}$ bonds, but only $60 \mathrm{VSE}$; it is therefore electrondeficient, and this electron deficiency is believed to play a determining role in the reactivity observed for this cluster (see below).

\section{HETEROATOM ABSTRACTION REACTIONS RELATED TO HDS}

Among the clusters synthesized to date the reactivity of only clusters 1 and 2 has been studied extensively. These were chosen for initial study because their elemental composition $(\mathrm{Mo} / \mathrm{Co} / \mathrm{S})$ most closely resembles that of industrial HDS catalysts, and because cluster 1, when adsorbed on alumina, appears to form the same active site for thiophene HDS catalysis as is found on an industrial catalyst. ${ }^{21}$

Cluster 1 reacted with neat thiophene at $110-$ $150{ }^{\circ} \mathrm{C}$ to give a quantitative yield of cubane 2 and traces of a black solid (possibly $\mathrm{C}_{n} \mathrm{H}_{n}$ ). ${ }^{22}$ When the reaction was conducted at $150^{\circ} \mathrm{C}$ under $15 \mathrm{~atm}$ of hydrogen, cluster 2 was again formed in quantitative yield, the black solid was not present, and GC MS analysis of the head gases showed the presence of methane, ethane, ethylene, propane, propene, butane and butenes (Eqn [1]). Compared with the products produced by the heterogeneously catalyzed HDS of thiophene, ${ }^{21}$ the homogeneous desulfurization reaction produced more cracking $\left(\mathrm{C}_{1}-\mathrm{C}_{3}\right.$ hydrocarbons) and more hydrogenation (saturated hydrocarbons vs olefins). Neither cluster 1 nor 2 reacts with hydrogen $\left[500 \mathrm{psi}(3450 \mathrm{kPa}), 150^{\circ} \mathrm{C}\right]$, so the hydrogenation reactions must occur on an intermediate thiophene-cluster complex.

Despite our best efforts, we have been unable to isolate or detect an intermediate thiophenecluster complex in the conversion depicted in Eqn [1]. However, since it is known that thiophene can be constructed from two acetylene molecules and a sulfided metal surface, ${ }^{2.3}$ we attempted to construct a thiophene-cluster complex by reacting 1 with acetylenes. 


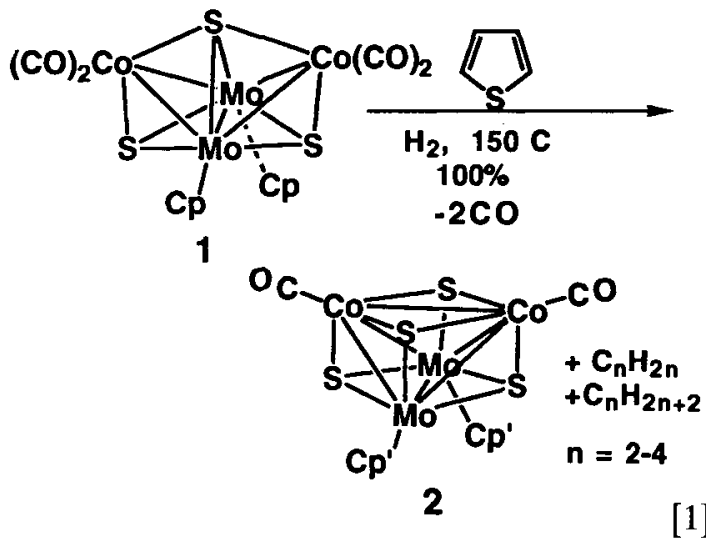

Cluster 1 reacted with one equivalent of alkyne, e.g. $\mathrm{PhCCH}, \mathrm{PrCCPr}, \mathrm{HCCH}, \mathrm{PhCCPh}$, to give the mono-alkyne adduct, 8 (Eqn [2]). ${ }^{24}$ Loss of two moles of $\mathrm{CO}$ in the formation of 8 results in a 60-VSE saturated cluster if the alkyne is considered to be a four-electron donor. The chemical shifts of the alkyne carbons, $\delta 199$ for the PrCCPr complex, are in the range of fourelectron donor alkynes. ${ }^{25}$

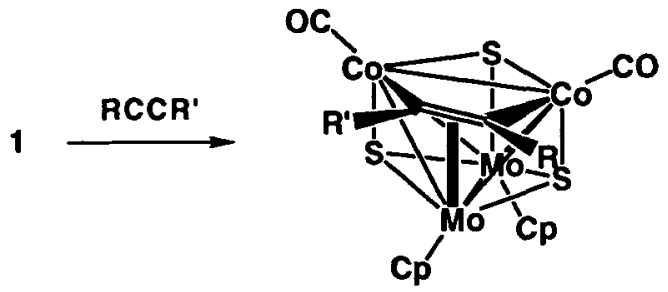

(8)

Reaction of the monoalkyne adducts with more alkyne, or reaction of cluster 1 with excess alkyne, resulted in the formation of bis(alkyne) adducts 9 which feature a molybdenacyclopentadiene formed by coupling of the two alkyne moieties (Eqn [3]).

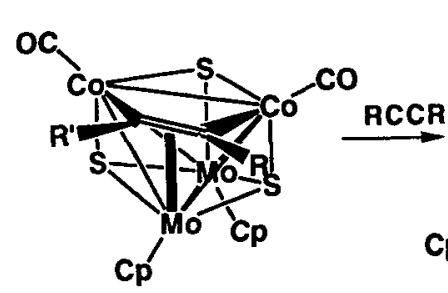

(8)

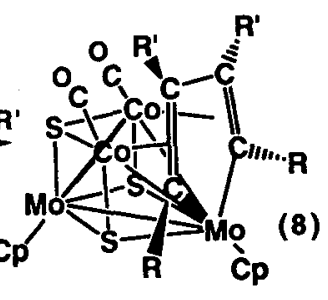

(9)
[3]

The bis(alkyne) adducts have $62 \mathrm{VSE}$ if the $\mathrm{R}_{4} \mathrm{C}_{4}$ fragment donates six electrons to the cluster core. One might expect these clusters to have five $\mathrm{M}-\mathrm{M}$ bonds but all metal-metal contacts in 9
$\left(\mathrm{R}=\mathrm{Ph}, \quad \mathrm{R}^{\prime}=\mathrm{H}\right) \quad$ are within bonding distances: $\quad$ Mo-Mo $=2.918 \AA, \quad$ Mo-Co $=$ $2.70-2.78 \AA \quad($ av. $=2.74 \pm 0.04 \AA), \quad \mathrm{Co}-\mathrm{Co}=$ $2.616 \AA$. The corresponding distances in the electron-precise mono-alkyne adduct are: $\mathrm{Mo}-\mathrm{Mo}=2.709 \AA, \quad$ Mo-Co=2.60-2.70 $\AA$ (av. $=2.66 \pm 0.04 \AA$ ),$\quad \mathrm{Co}-\mathrm{Co}=2.576 \AA$. Thus, the Mo-Mo distance in 9 is elongated by some $0.2 \AA$, the Mo-Co distance by $0.1 \AA$, and the Co-Co distance by $0.04 \AA$. These elongations probably reflect the fact that 9 is electron-rich with the extra pair of electrons in a molecular orbital with $\mathbf{M}-\mathbf{M}$ anti-bonding character.

Attempts to prepare a thiophenic adduct by insertion of sulfur into the metallacyclic ring in 9 $\left(\mathrm{RCCR}^{\prime}=\mathrm{PhCCH}\right)$ by reaction with $\left(\mathrm{PhCH}_{2} \mathrm{~S}\right)_{2} \mathrm{~S}$ or propylene sulfide were unsuccessful. Complete decomposition occurred with benzyl trisulfide, and no reaction occurred with propylene sulfide.

Cluster 1 cleanly extracted the sulfur atom from alkyl thiols, $\mathrm{RSH}$, to produce quantitative yields of cubane 2 and the corresponding hydrocarbon, $\mathrm{RH}$, where $\mathrm{R}=\mathrm{t}$-butyl, s-pentyl or phenyl. ${ }^{22,26}$ No traces of alkenes or other hydrocarbons were observed with the butyl or pentyl thiols, a result which suggests that the thiol group is not removed as $\mathrm{SH}^{-}$since the resulting carbocation would be expected to eliminate $\mathrm{H}^{+}$to form some alkene or rearranged hydrocarbon. cis-2-Butene sulfide reacted with cluster 1 to give cubane 2 and cis-2butene only, a result again suggestive of a concerted sulfur abstraction mechanism.

Sulfur was also abstracted from t-butyl isothiocyanate, tBuNCS. ${ }^{22.26}$ In this case, the resultant isocyanide, $\mathrm{tBuNC}$, displaced some of the carbonyl groups on both the starting cluster 1 and the product cluster 2 (Scheme 1). The substituted clusters may be prepared independently by the reactions of cluster 1 or 2 with $R N C(R=t B u$ or $\mathrm{Me}$ ). The isocyanide-substituted cluster 1 also reacts with isothiocyanates to give substituted cubane 2 and RNC. The reactions of cluster 1 with thioketones $\mathrm{Ar}_{2} \mathrm{CS}$ are currently under study.

Since the conversion of cluster 1 to cubane 2 was quantitative as determined by in situ NMR experiments, a long-lived homogeneous catalytic cycle for desulfurization would be possible if cubane 2 could be converted back to cluster 1 . Clearly, CO must be added to 2 for its conversion back to 1 , and one atom of sulfur per cluster must be removed. In HDS catalysis, sulfur is removed as $\mathrm{H}_{2} \mathrm{~S}$ by reduction of the catalyst surface with hydrogen. Cluster 2 did not react with hydrogen 


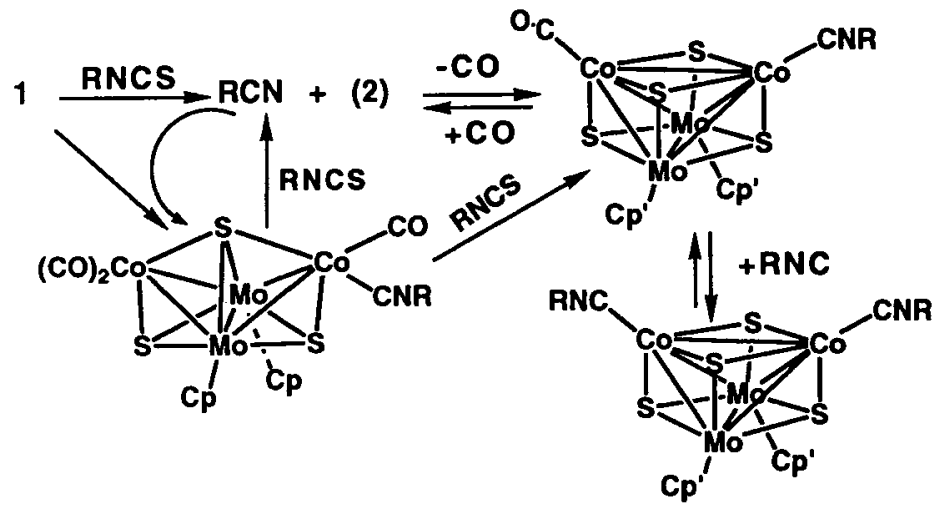

Scheme 1

alone, and with $\mathrm{H}_{2} / \mathrm{CO}$ mixtures [ $50 \mathrm{psi}(345 \mathrm{kPa}$ ) $\left.\mathrm{CO}, 400 \mathrm{psi}(2760 \mathrm{kPa}) \mathrm{H}_{2}, 200^{\circ} \mathrm{C}\right] 2$ fragmented and recombined to produce high yields of $\mathrm{Cp}_{3} \mathrm{Mo}_{3} \mathrm{CoS}_{4}$ (CO) (10, Fig. 2).

Increasing the $\mathrm{CO}$ pressure to $1000 \mathrm{psi}$ $(6900 \mathrm{kPa})$ and decreasing the temperature to $150{ }^{\circ} \mathrm{C}$ led to a $20 \%$ conversion of 2 to 1 in $12 \mathrm{~h}$. The only observed gaseous product was COS. Since COS reacts with 1 to give 2 and $\mathrm{CO}$, the $20 \%$ conversion probably represents the thermodynamic equilibrium value in the closed pressure reactor, but this has not been established. Nevertheless, even a partial conversion of 2 back to 1 should suffice to establish a catalytic carbonyldesulfurization (CDS) cycle as shown in Scheme 2.

Initial attempts to desulfurize thiophene under $\mathrm{CO}$ and hydrogen led to no reaction. We assumed that the thiophene simply could not compete for a coordination site with the high concentration of $\mathrm{CO}$ necessary to convert 2 to 1 . Failure of the thiophene to coordinate to 1 naturally leads to no reaction.

A more basic organic sulfide, thiopnenol, was then tried. At $150^{\circ} \mathrm{C}$ and $1000 \mathrm{psi}(6900 \mathrm{kPa})$ of $\mathrm{CO}, \mathrm{PhSH}$ reacted with 1 to give benzene $(6 \%)$, benzaldehyde $(38 \%)$, $\mathrm{PhC}(\mathrm{O}) \mathrm{SPh}(25 \%)$, and two unidentified organic products $(31 \%)$, as well

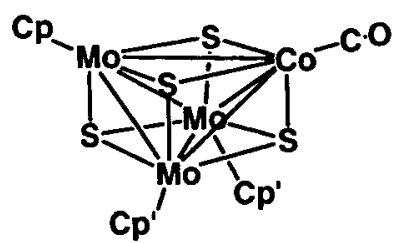

(10)

Figure 2

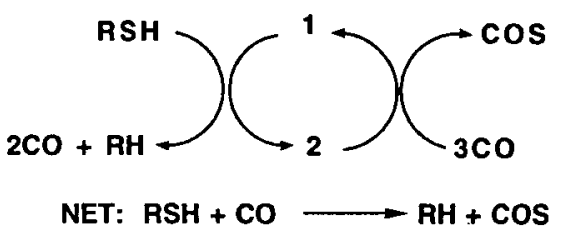

Scheme 2

as a $144 \%$ yield of $\mathrm{PhSSPh}$ (yields based on 1 consumed). The yield of 2 was reduced from quantitative to near $80 \%$ and some unidentified metal-sulfur compounds were also formed. Although the production of diphenyl disulfide appears to be catalytic, the sum of the yields of the desulfurized products is nearly equal to the total amount of cluster 1 reacted, so the desulfurization process does not appear to be catalytic.

Isolation of carbonylated products, e.g. benzaldehyde and $\mathrm{PhC}(\mathrm{O}) \mathrm{SPh}$, suggests the formation of a metal-phenyl bond during the desulfurization step. Under high $\mathrm{CO}$ pressure, the $\mathrm{M}-\mathrm{Ph}$ bond undergoes insertion by $\mathrm{CO}$ to form a metal acyl, $\mathrm{M}-\mathrm{C}(\mathrm{O}) \mathrm{Ph}$. This species may react with the excess $\mathrm{PhSH}$ in solution to form either $\mathrm{PhCHO}$ or $\mathrm{PhC}(\mathrm{O}) \mathrm{SPh}$. If similar metal-alkyls are formed during the desulfurization of alkylthiols, then the rate of reductive elimination of alkane must be much greater than the rate of $\beta$-hydride elimination to account for the lack of alkenes observed in those reactions (see above).

In none of these experiments were we able to observe intermediates in the desulfurization process. Apparently, reaction steps subsequent to the initial thiol or thiophene coordination are faster than the first complexation step. In order to make the initial complexation more facile, we turned to studying the reactions of 1 with phosphines in hopes of detecting or isolating 
intermediates that would provide mechanistic information.

Cluster 1 reacted readily with phenylphosphine, $\mathrm{PhPH}_{2}$, at $80^{\circ} \mathrm{C}(1 \mathrm{~h})$ to give a $65 \%$ yield of the mono-substituted adduct, $\mathrm{Cp}_{2} \mathrm{Mo}_{2} \mathrm{Co}_{2} \mathrm{~S}_{3}(\mathrm{CO})_{3}\left(\mathrm{PH}_{2} \mathrm{Ph}\right)(11)(\mathrm{Eqn} 4) .{ }^{27}$

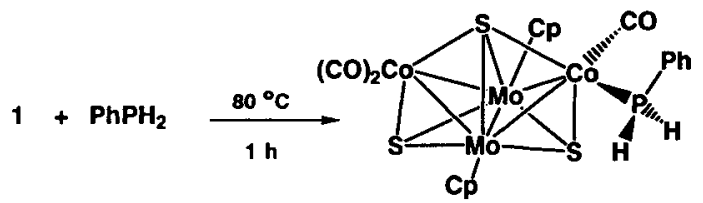

(11)

The reaction of cluster 11 with excess $\mathrm{PhPH}_{2}$ in refluxing benzene $(2 \mathrm{~h})$ produced the phosphinidene cluster $12\left(\delta^{31} \mathrm{P}=452 \mathrm{ppm}\right)$ and its $\mathrm{PhPH}_{2}$ adduct, 13 (Eqn [5]). ${ }^{27}$ In this reaction, presumably $\mathrm{CO}$ and hydrogen are lost, so the 'phosphinidene abstraction' is isoelectronic and isolobal to a sulfur abstraction from $\mathrm{H}_{2} \mathrm{~S}$. The adduct 13 was readily converted back to the phosphinidene cubane cluster 12 simply by bubbling $\mathrm{CO}$ through solutions of 13 at room temperature. ${ }^{27}$

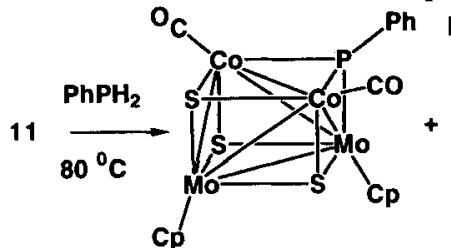

(12)

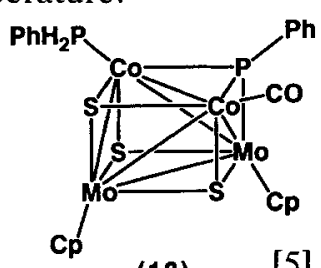

(13)
[5]

Abstraction of $\mathrm{PhP}$ from $\mathrm{Ph}_{2} \mathrm{PH}$ by 1 to give 12 and $\mathrm{PhH}$ would be a direct analogue of the reaction of 1 with $\mathrm{PhSH}$ to give 2 and $\mathrm{PhH}$. Accordingly, 1 was allowed to react with $\mathrm{Ph}_{2} \mathrm{PH}$ in refluxing benzene. In this case, the $\mathrm{CO}$ substitution reactions were faster than with $\mathrm{PhPH}_{2}$ and both mono- and bisadducts of 1 were isolated, the latter in cis/trans isomers (Eqn [6]). ${ }^{27}$ Further heating of the solution led to a complex mixture that contained small amounts of 12 and $\mathrm{PhH}$. Perhaps the increased basicity of $\mathrm{Ph}_{2} \mathrm{PH}$ compared with $\mathrm{PhPH}_{2}$ leads to competing reactions that abstract sulfur from the clusters.

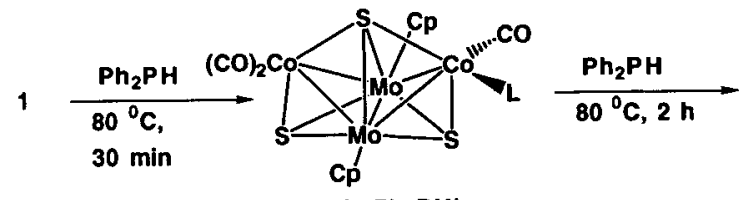

(14, $\mathrm{L}=\mathrm{Ph}_{2} \mathrm{PH}$ )

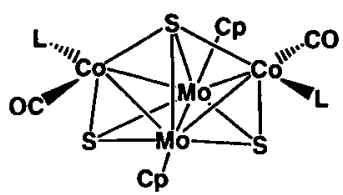

trans-15

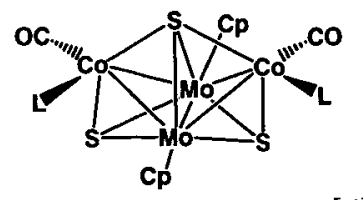

cis-15
The fact that $\mathrm{PhPH}_{2}$ and $\mathrm{Ph}_{2} \mathrm{PH}$ reacted with 1 at different rates under the same conditions suggested an associative mechanism of $\mathrm{CO}$ substitution. Indeed, addition of more basic nucleophiles, e.g. $\mathrm{Me}_{3} \mathrm{P}$ or $\mathrm{RNC}(\mathrm{R}=\mathrm{tBu}, \mathrm{Me})$, at $-50^{\circ} \mathrm{C}$ gave rise to red intermediates. The $\mathrm{Me}_{3} \mathrm{P}$ intermediate was isolated and shown by $\mathrm{X}$-ray crystallography to be a simple adduct in which the $\mathrm{Co}-\mathrm{S}$ bond had been displaced by $\mathrm{Co}-\mathrm{PMe}_{3}{ }^{28}$ Spectroscopic characteristics show that the RNC adducts have the same structure (Eqn [7]). It is interesting to note that the reaction depicted in Eqn [7] transforms the 60-VSE unsaturated cluster 1 to an electronically saturated 62 -VSE butterfly cluster, 16.

1

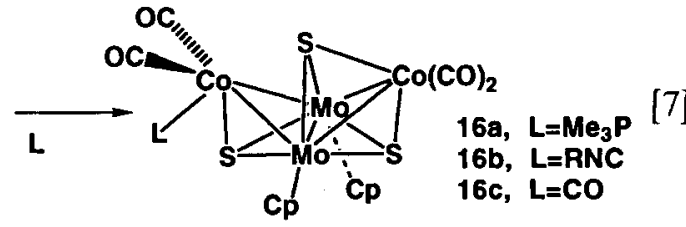

As the temperature was increased, the adducts 16a and 16b displayed different reactivities. In $16 \mathrm{a}$, the $\mu_{3}$-sulfur ligand displaced the $\mathrm{Me}_{3} \mathrm{P}$ ligand and the starting cluster 1 was regenerated. In $16 b$, however, a CO group was preferentially lost, leading to $\mathrm{CO}$ substitution. Thus, we have a system, depicted in Eqn [8], that displays three types of behavior depending on the relative magnitudes and temperature dependence of $k_{1}, k_{-1}$ and $k_{2}$.

$$
1+L \frac{k_{1}}{k_{-1}} 1 \cdot L \frac{k_{2}}{-C O} \text { [1-L-CO ] }
$$

Assuming steady state, the concentration of [1-L] is $K[1][\mathrm{L}] /\left(1+k_{2} / k_{-1}\right)$ where $K=k_{1} / k_{-1}$. With less basic phosphines, e.g. $\mathrm{PhPH}_{2}$, etc. $K$ is small relative to $k_{2} / k_{-1}$ and detectable concentrations of the adduct do not form. With $\mathrm{Me}_{3} \mathrm{P}$ at low temperature, $K$ is large with respect to $1+k_{2} / k_{-1}$ and the adduct is the major species present. At higher temperatures, $k_{-1}$ increases faster than either $k_{1}$ or $k_{2}$ so the adduct decomposes back to starting materials. When $\mathrm{L}=\mathrm{RNC}, K$ is large at lower temperatures but $k_{2}$ increases fastest as the temperature is raised and $\mathrm{CO}$ substitution is observed.

This adduct formation is of importance in the attempts to create a CDS catalytic cycle (see Scheme 2 above). With $\mathrm{L}=\mathrm{CO}$, the $\mathrm{CO}$ substitution step is degenerate, i.e. $k_{2}=k_{-1}$ and the concentration of a $62-\mathrm{VSE}$ adduct, 16c, will depend 
on the equilibrium constant, $K$, and the $\mathrm{CO}$ pressure. High-pressure NMR and IR studies ${ }^{28}$ have shown that $K_{\mathrm{p}}=6.8 \times 10^{-3} \mathrm{~atm}$ at $\mathrm{ca} 20^{\circ} \mathrm{C}$ which corresponds to a $31 \%$ conversion of 1 into $16 \mathrm{c}$ at ambient temperature with $P_{\mathrm{co}}=1000 \mathrm{psi}$ $(6900 \mathrm{kPa})$. Hence, under catalytic conditions, a sizeable fraction of 1 will exist as the 62-VSE adduct $16 c$. The reactivity of $16 \mathrm{c}$ with thiols may lead to new reaction pathways and new products, and eventually bleed off the working reservoir of clusters 1 and 2 , thus halting the catalytic cycle.

\section{SURFACE REACTIVITY}

It has been demonstrated that clusters 1 and 6 react with surfaces of oxide supports to produce bimetallic surface ensembles. ${ }^{21,29}$ These ensembles are sulfur-tolerant $\mathrm{CO}$ methanation catalysts. ${ }^{30}$ After reduction and sulfidation, the $\mathrm{MO} / \mathrm{Co} / \mathrm{S}$ cluster 1 appears to form the same active site for thiophene HDS catalysis as is found on a commercial HDS catalyst. ${ }^{21,31}$ Similar treatment of the cubane cluster 2 adsorbed on $\mathrm{Al}_{2} \mathrm{O}_{3}$ gives a catalyst only one-tenth as active as that formed from $1 .{ }^{32}$ Thus surprising result suggests that even clusters with very similar stoichiometries and structures may exhibit different surface reactivity which leads to different surface ensembles.

Quantitative fits of both iron and molybdenum EXAFS data have been made of (a) pure crystalline cluster 6, (b) the cluster adsorbed on $\mathrm{Al}_{2} \mathrm{O}_{3}$ from $\mathrm{CH}_{2} \mathrm{Cl}_{2}$ solution followed by vacuum drying at room temperature, (c) the adsorbed cluster heated to $120^{\circ} \mathrm{C}$, and (d) adsorbed species heated to $400{ }^{\circ} \mathrm{C}$ under hydrogen. ${ }^{21,33}$ Initial deposition and drying resulted in essentially no change of the molybdenum EXAFS, but the intensity of the iron $\mathrm{CO}$ vectors decreases. Quantitative fitting suggested the loss of $2.8 \mathrm{CO}$ groups per cluster.

After heating to $120^{\circ} \mathrm{C}$ (the temperature at which TPDE showed a burst of $5 \mathrm{CO} /$ cluster to be evolved), all cluster-like features were lost from the spectra and only metal-oxygen vectors were found in the Fourier transform. The best fit showed iron surrounded by six oxygen atoms $(r=1.86 \AA)$ in a distorted octahedral array, and the molybdenum appeared to be surrounded by 4-5 oxygen atoms. These results are consistent with the sequence of events depicted in Scheme 3.

Similar data on cluster 1 have been collected but not analyzed in detail as yet. However, the cobalt XANES (normalized edge spectra) show an interesting result (Figure 3). This $\mathrm{Mo} / \mathrm{Co} / \mathrm{S}$ cluster appears to be much more reactive toward the $\mathrm{Al}_{2} \mathrm{O}_{3}$ surface than the $\mathrm{Mo} / \mathrm{Fe} / \mathrm{S}$ cluster 6 . TPDE of the former showed less than one CO per cluster evolved upon heating to $400{ }^{\circ} \mathrm{C}$ under hydrogen (indicating most of the $\mathrm{CO}$ was evolved in the vacuum drying step). The XANES of adsorbed cluster shows no resemblance to the pure cluster (Fig. 3), as opposed to the corresponding spectra for 6 (see Ref. 21 for representative spectra).

The surprising feature about the spectra shown in Fig. 3 is that the environment of the cobalt atom did not change after heating to $400{ }^{\circ} \mathrm{C}$ under hydrogen, nor after sulfiding with $15 \% \quad \mathrm{H}_{2} \mathrm{~S}$ in hydrogen at $400{ }^{\circ} \mathrm{C}$. The sulfiding step increased the activity of the catalyst 10 -fold ${ }^{21}$ but caused no change in the cobalt environment! This result is simply not in accord with Topsøe's model for the active site (see Introduction, and Ref. 7). Either

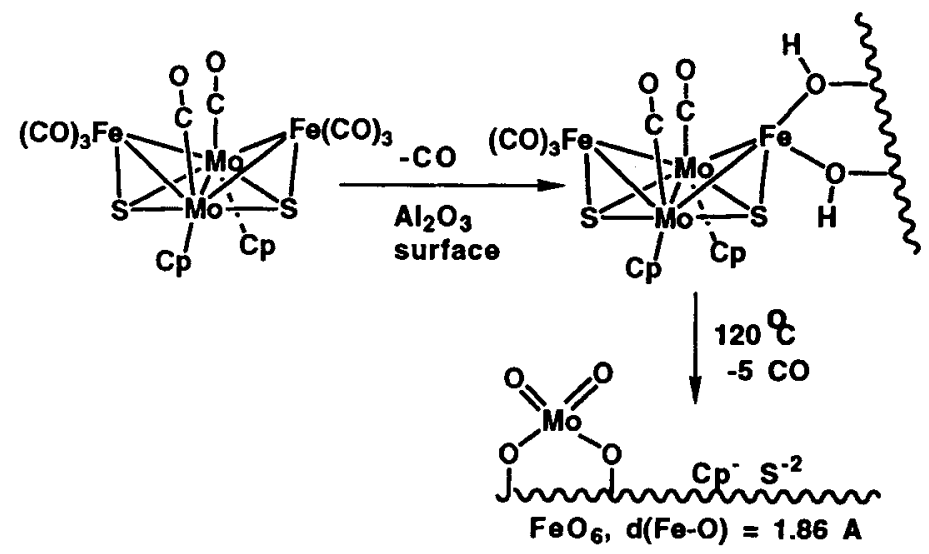

Scheme 3 


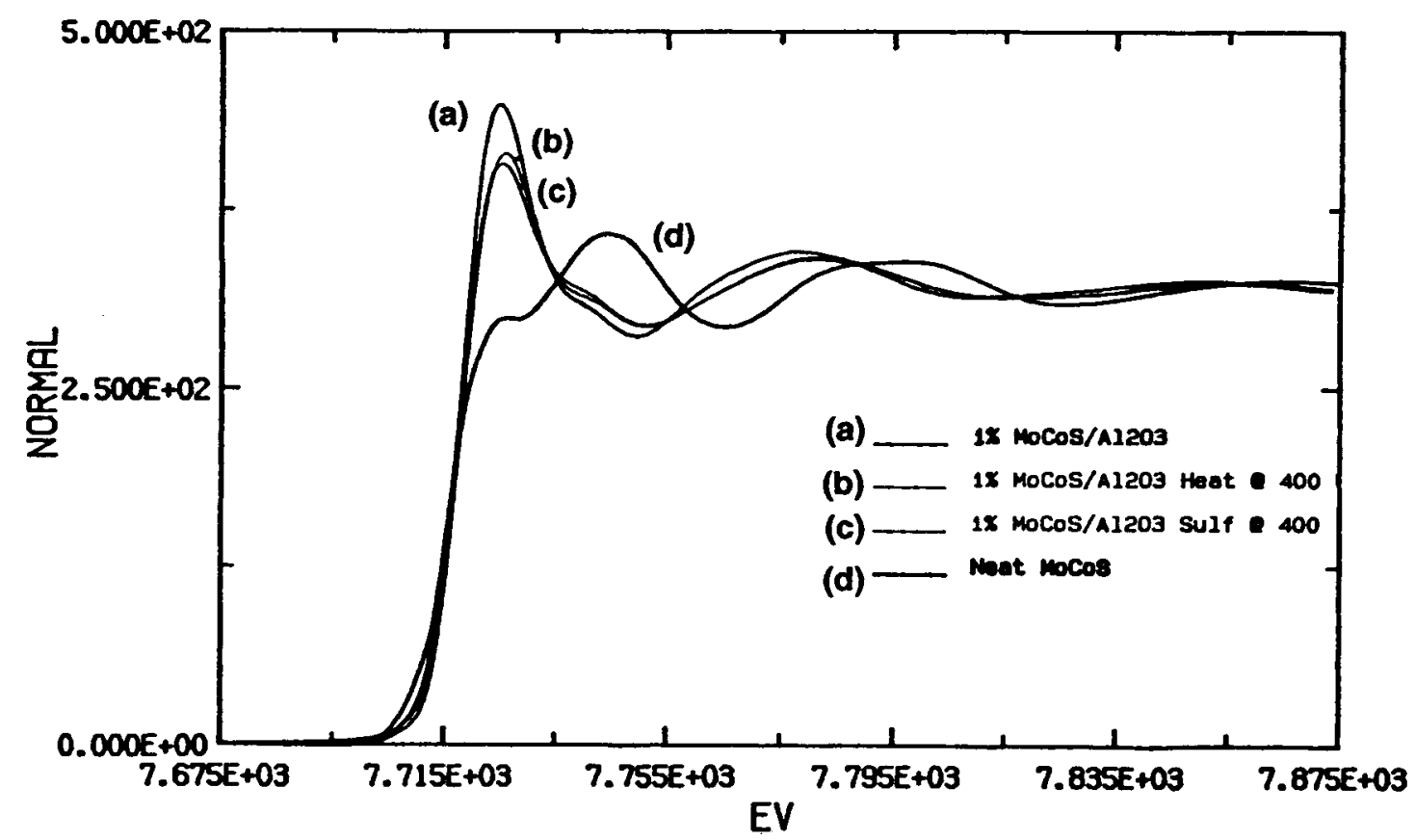

Figure 3 Normalized cobalt edge spectra for $\mathrm{Cp}_{2} \mathrm{Mo}_{2} \mathrm{Co}_{2} \mathrm{~S}_{3}(\mathrm{CO})_{4}(1)$ : (a) adsorbed on $\mathrm{Al}_{2} \mathrm{O}_{3}$ and dried at $20^{\circ} \mathrm{C}$; (b) as in (a) heated to $400{ }^{\circ} \mathrm{C}$ under hydrogen; (c) as in (a) treated with $15 \% \mathrm{H}_{2} \mathrm{~S}$ in hydrogen at $400{ }^{\circ} \mathrm{C}$; (d) pure crystalline cluster.

the cluster-derived catalysts have a quite different active site (but one that coincidentally gives the same product distribution and same specific activity as a conventional $\mathrm{Co} / \mathrm{Mo} / \mathrm{S}$ catalyst ${ }^{21}$ ), or the current model needs to be refined as to the role of the promoter atom.

\section{CONCLUSIONS}

Homogeneous reactions of a $\mathrm{Mo} / \mathrm{Co} / \mathrm{S}$ cluster (1) show some similarities to the heterogeneous sulfur abstraction reactions catalyzed by $\mathrm{Co} / \mathrm{Mo} / \mathrm{S}$ compositions. The cluster reactivity opens the way for further mechanistic investigations that may have relevance to the heterogeneously catalyzed reactions. Furthermore, the $\mathrm{Mo} / \mathrm{Co} / \mathrm{S}$ clusters are convenient precursors to supported bimetallic phases. By approaching these surface phases from a totally different starting point, and following the evolution of the surface species as a function of pre-treatment, etc., one may gain new insights into the nature of the surface species and the role of the promoter metals.

Acknowledgements The author wishes to thank all his coworkers, referenced throughout the text, for their invaluable contributions to the work described here. This research was supported by a grant from the National Science Foundation (CHE-8619864).

\section{REFERENCES}

1. Amberg, C H J. Less Common Metals, 1974, 36: 339

2. Grange, P Catal. Rev.-Sci. Eng. 1980, 21: 135

3. Ratnasamy, P and Sivasanker, S Catal. Rev.-Sci. Eng., 1980, 22: 401

4. Massoth, F E Adv. Catal., 1978, 27: 265

5. Chianelli, R R, Pecoraro, T A, Halbert, T R, Pan, W-H and Stiefel, E I J. Catal., 1984, 86: 226

6. Prins, R, de Beer, V H J and Somorjai, G A Catal. Rev.-Sci. Eng. 1989, 31: 1

7. Topsøe, H and Clausen, B S Catal. Rev.-Sci. Eng., 1984, 26: 395

8. Roxlo, C B, Daage, M, Ruppert, A F and Chianelli, R R J. Catal., 1986, 100: 176

9. Zwart, J and Snel, R J. Molec. Catal., 1985, 30: 305

10. Rauchfuss, T B Prog. Inorg. Chem., 39: 260

11. Angelici, R J Accts. Chem. Res., 1988, 21: 387

12. For a review of metal alkoxide chemistry, see Bukro, W E and Chisholm, M H Adv. Organomet. Chem., 1987, 27: 311

13. For a review of thiolate chemistry, see Müller, A, Diemann, E, Jostes, $\mathrm{R}$ and Bögge, $\mathrm{H}$ Angew. Chem. Int. Ed. Engl., 1981, 20: 934

14. Rakowski DuBois, M Chem. Rev., 1989, 89: 1 
15. Lopez, L, Godziela, G and Rakowski DuBois, M Organometallics, 1991, 10: 2660

16. Adams, R D Polyhedron, 1985, 4: 2003

17. Curtis, M D, Williams, P D and Butler, W M, Inorg. Chem., 1988, 27: 2853

18. Williams, P D and Curtis, M D J. Organomet. Chem., 1988, 352: 109

19. Li, P and Curtis, M D Inorg. Chem., 1990, 29: 1242

20. Li, P and Curtis, M D J. Am. Chem. Soc., 1989, 111: 8279

21. Curtis, M D, Penner-Hahn, J E, Schwank, J, Baralt, O, McCabe, D J, Thompson, L and Waldo, G Polyhedron, 1988, 7: 2411

22. Riaz, U, Curnow, O and Curtis, M D J. Am. Chem. Soc., 1991, 113: 1416

23. Gentle, T M, Tsai, C T, Walley, K P and Gellman, A J Catal. Lett., 1989, 2: 19

24. Riaz, U and Curtis, M D Organometallics, 1990, 9: 2647
25. Templeton, J L and Ward, B C J. Am. Chem. Soc., 1980, 102: 3288

26. Curnow, $\mathrm{O} J$ and Curtis, M D (unpublished results)

27. Curnow, O J, Kampf, J W and Curtis, M D Organometallics, 1991, 10: 2546

28. Curnow, O J, Kampf, J W, Curtis, M D and Mueller, B L Organometallics, 1992, 11: in press

29. Curtis, M D, Schwank, J, Penner-Hahn, J, Thompson, L, Baralt, O and Waldo, G Mater. Res. Soc. Symp. Proc., 1988, 111: 331

30. Thompson, L T Jr, Schwank, J and Curtis, M D Am Inst. Chem. Eng. J., 1989, 35: 109

31. Carvill, B J and Thompson, L T Appl. Catal., 1991, 75: 249

32. McCabe, D J and Curtis, M D (to be published)

33. Waldo, G, Penner-Hahn, J and Curtis, M D (to be published) 